ARTICLE

Received 21 May 2014 | Accepted 10 Aug 2014 | Published 11 Sep 2014

DOI: $10.1038 /$ ncomms5948

\title{
Synergistic geometric and electronic effects for electrochemical reduction of carbon dioxide using gold-copper bimetallic nanoparticles
}

Dohyung Kim${ }^{1}$, Joaquin Resasco ${ }^{2}, \mathrm{Yi}_{\mathrm{i}} \mathrm{Yu}^{3}$, Abdullah Mohamed Asiri ${ }^{4}$ \& Peidong Yang ${ }^{1,3,5}$

Highly efficient and selective electrochemical reduction of carbon dioxide represents one of the biggest scientific challenges in artificial photosynthesis, where carbon dioxide and water are converted into chemical fuels from solar energy. However, our fundamental understanding of the reaction is still limited and we do not have the capability to design an outstanding catalyst with great activity and selectivity a priori. Here we assemble uniform gold-copper bimetallic nanoparticles with different compositions into ordered monolayers, which serve as a well-defined platform to understand their fundamental catalytic activity in carbon dioxide reduction. We find that two important factors related to intermediate binding, the electronic effect and the geometric effect, dictate the activity of gold-copper bimetallic nanoparticles. These nanoparticle monolayers also show great mass activities, outperforming conventional carbon dioxide reduction catalysts. The insights gained through this study may serve as a foundation for designing better carbon dioxide electrochemical reduction catalysts.

\footnotetext{
${ }^{1}$ Department of Materials Science and Engineering, University of California, Berkeley, California 94720, USA. ${ }^{2}$ Department of Chemical and Biomolecular Engineering, University of California, Berkeley, California 94720, USA. ${ }^{3}$ Department of Chemistry, University of California, Berkeley, California 94720 , USA. ${ }^{4}$ Center of Excellence for Advanced Materials Research (CEAMR), King Abdulaziz University, P.O. Box 80203, Jeddah 21589, Saudi Arabia.

${ }^{5}$ Kavli Energy Nanosciences Institute, Berkeley, California 94720, USA. Correspondence and requests for materials should be addressed to P.Y.

(email: p_yang@berkeley.edu).
} 
E nergy and environmental problems represent one of the greatest challenges facing mankind in this century. Despite tremendous efforts to develop renewable energy sources ${ }^{1-7}$, still the majority of energy used is derived from non-renewable fossil fuels. One attractive option to solve this problem is the electrochemical reduction of carbon dioxide into fuels ${ }^{8}$. Reducing carbon dioxide, an abundant carbon source, into value-added fuels using a renewable energy input (that is, artificial photosynthesis) would allow us to reduce our dependence on conventional fossil fuels, mitigate $\mathrm{CO}_{2}$ emissions and make our society more sustainable. Furthermore, chemical fuels produced from carbon dioxide could be readily implemented in the current energy infrastructure, allowing a quick and smooth transition towards a renewable energy society. However, fundamental scientific challenges remain for the basic understanding of electrochemical carbon dioxide reduction process, which limit our capability of rationally designing high-performance $\mathrm{CO}_{2}$ reduction catalysts. The $\mathrm{CO}_{2}$ reduction reaction itself is much more complex than the related hydrogen evolution (HER) or oxygen evolution reaction (OER), as multiple electron and proton coupling steps are typically involved in several different reaction pathways, leading to many possible final products ${ }^{9,10}$. In addition, most of the materials studied as $\mathrm{CO}_{2}$ reduction catalysts to date require large over-potentials and typically are also active for $\mathrm{HER}^{11,12}$, which results in low turnover rates (TOR) to $\mathrm{CO}_{2}$ reduction products at moderate over-potentials. Furthermore, there is an additional issue of catalyst deactivation, which must be addressed for sustained production of fuels from $\mathrm{CO}_{2}$ (refs 9,13).

Despite the limitations on the fundamental understanding of electrochemical reduction of $\mathrm{CO}_{2}$, there have been great efforts in the past few decades to address this issue either experimentally ${ }^{8-19}$ or theoretically $y^{20-22}$. A wide variety of metal electrodes have been examined ${ }^{9}$ as $\mathrm{CO}_{2}$ reduction catalysts with a focus on $\mathrm{Cu}^{10,11,14,15,18}, \mathrm{Au}^{16,23}$ and $\mathrm{Sn}^{17}$, as other metals are mostly inactive. In particular, $\mathrm{Cu}$ has gained the most interest because of its capability to reduce $\mathrm{CO}_{2}$ into hydrocarbon fuels, such as methane or ethylene. Even though some progress has been made for these catalysts in terms of increasing TOR and reducing over-potentials, there is still much to be learned to develop a better understanding of the reaction and the principles required to design an efficient catalyst.

More recently, one approach that has been suggested to enhance the catalytic activity and selectivity for $\mathrm{CO}_{2}$ reduction is alloying $^{21,22}$. By alloying, it is believed that we might be able to tune the binding strength of intermediates on a catalyst surface to enhance the reaction kinetics for $\mathrm{CO}_{2}$ reduction. Nanoparticles provide an ideal platform for studying this effect. Through appropriate synthetic processes, a wide range of compositions, sizes and shapes can be accessed, allowing for deeper understanding of catalyst performance through precise control of active sites ${ }^{24}$. Furthermore, nanoparticles have high surface-tovolume and surface-to-mass ratio, which are advantageous for achieving high mass activity ${ }^{23,24}$.

For this reason, we use $\mathrm{Au}-\mathrm{Cu}$ bimetallic nanoparticles in a monolayer platform to study their $\mathrm{CO}_{2}$ reduction activity. Using this monolayer platform, we are able to quantitatively compare activity and selectivity as a function of $\mathrm{Au}$ and $\mathrm{Cu}$ composition. Moreover, we can achieve efficient catalyst loading, resulting in a significant enhancement in its mass activity. Insights gained through this quantitative comparison will help to develop design principles for high-performance $\mathrm{CO}_{2}$ reduction catalysts.

\section{Results}

Characterization of $\mathrm{Au}-\mathrm{Cu}$ bimetallic nanoparticle catalysts. The $\mathrm{Au}-\mathrm{Cu}$ bimetallic system has been suggested as a potential
$\mathrm{CO}_{2}$ reduction catalyst in previous reports ${ }^{25,26}$. However, there has not been a systematic study to precisely understand its activity as function of its composition. Furthermore, $\mathrm{Au}$ and $\mathrm{Cu}$ have been identified to possess intermediate binding strength favourable for $\mathrm{CO}_{2}$ reduction ${ }^{21,22}$; hence, they serve as a good starting point to tune the energetics of the intermediate binding to achieve even higher activity.

Figure 1a is a transmission electron microscopy (TEM) image of $\mathrm{AuCu}_{3}$ nanocrystals as synthesized. The synthetic procedures were modified from the methods reported previously ${ }^{27}$. Nanoparticles with different stoichiometric ratios of $\mathrm{Au}$-to- $\mathrm{Cu}$ $\left(\mathrm{Au}, \mathrm{Au}_{3} \mathrm{Cu}, \mathrm{AuCu}, \mathrm{AuCu}_{3}\right.$ and $\left.\mathrm{Cu}\right)$ were synthesized in a similar manner with average size all close to $10 \sim 11 \mathrm{~nm}$ (Supplementary Figs 1 and 2), so that once assembled in a monolayer the catalytically active surface area for each electrode is essentially identical. The composition of each nanoparticle is confirmed using a number of methods. X-ray diffractometry (XRD) shows that the XRD pattern of each particle (Fig. 1b) matches with the corresponding characteristic patterns of each phase, although we find $\mathrm{Cu}$ to inevitably have a thin oxide shell, as can be seen from its XRD data ${ }^{28}$. In addition, $\mathrm{Au}$ and $\mathrm{Cu}$ atoms are randomly distributed within the lattice, which is expected considering the synthetic conditions ${ }^{29}$. Ultraviolet-visible spectroscopy is also a useful way to characterize nanoparticles. Au and $\mathrm{Cu}$ nanoparticles in their pure phase exhibit characteristic surface plasmon resonance (SPR) peaks at $\sim 523$ and $\sim 570 \mathrm{~nm}$ (refs 26,30,31). As the content of $\mathrm{Cu}$ increases in a pure $\mathrm{Au}$ nanoparticle by forming an alloy, the SPR peak of Au red-shifts towards the SPR peak of $\mathrm{Cu}$ with some broadening ${ }^{26,30}$ (Fig. 1c). The SPR peaks $\left(\lambda_{\mathrm{SPR}}=533 \mathrm{~nm}\right.$ for $\mathrm{Au}_{3} \mathrm{Cu}, 539 \mathrm{~nm}$ for $\mathrm{AuCu}$ and $549 \mathrm{~nm}$ for $\mathrm{AuCu}_{3}$ ) also match well with their composition 26,30 . Energy-dispersive X-ray spectroscopy was further used to confirm the composition of the nanoparticles (Supplementary Fig. 3). All these results confirmed that we have synthesized monodisperse $\mathrm{Au}-\mathrm{Cu}$ bimetallic nanoparticles with specific stoichiometric ratios of Au-to-Cu.

Nanoparticle assembly (or self-assembly) has been the subject of research for use of these unique structures in a wide variety of applications ${ }^{32-37}$. Among several approaches that lead to monolayer assemblies, we implemented the solvent evaporation-mediated self-assembly approach modified from its original method ${ }^{38}$, to fabricate nanoparticle monolayer platforms. Once assembled, the nanoparticle monolayers were transferred onto a glassy carbon substrate using the Langmuir-Schaefer method and tested in our electrochemical setup for $\mathrm{CO}_{2}$ reduction. Figure 1d shows a scanning electron microscopy image of a $\mathrm{AuCu}_{3}$ monolayer on a substrate. Most of the area is covered with the nanoparticle monolayer with high degree of ordering throughout the substrate, although it also contains some defective spots such as vacancies.

$\mathrm{CO}_{2}$ reduction activity of $\mathrm{Au}-\mathrm{Cu}$ bimetallic nanoparticles. To quantitatively determine and compare catalytic activity, the monolayered nanoparticles were analysed in our customdesigned electrochemical setup coupled with gas chromatography. The effluent gas from the electrochemical cell went through the sampling system of the gas chromatography and gas products were analysed in real-time, while the liquid products were analysed after the reaction by quantitative nuclear magnetic resonance spectroscopy. Electrolysis was performed under standard conditions of $0.1 \mathrm{M} \mathrm{KHCO}_{3}$ electrolyte saturated with $\mathrm{CO}_{2}$.

Figure 2a shows the overall activity of the $\mathrm{Au}-\mathrm{Cu}$ bimetallic nanoparticles under identical reaction conditions (Supplementary Figs 4 and 5). Pure $\mathrm{Cu}$ nanoparticles exhibit the lowest overall activity, while increasing the Au content enhances the activity up 
a

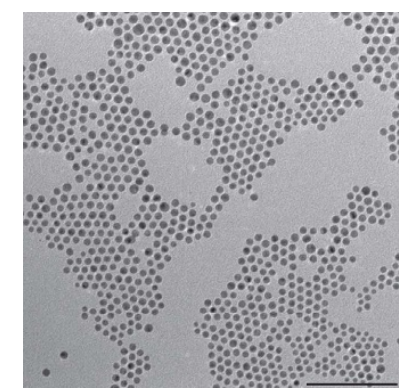

C

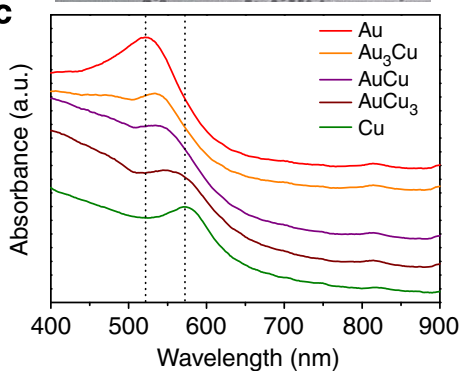

b

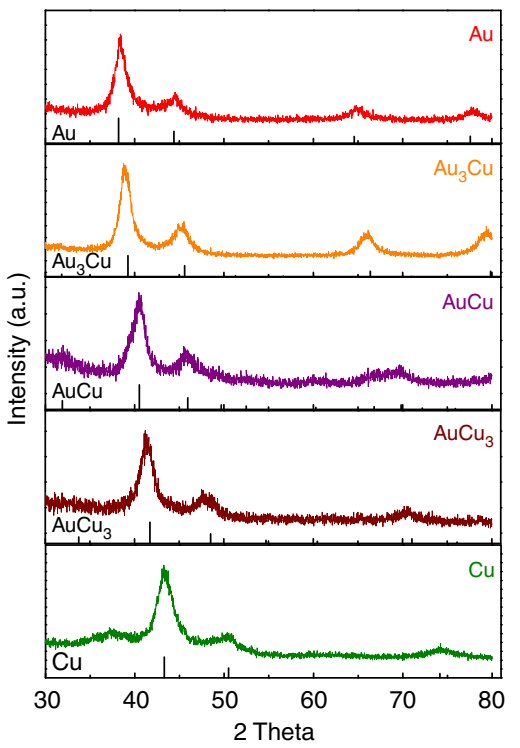

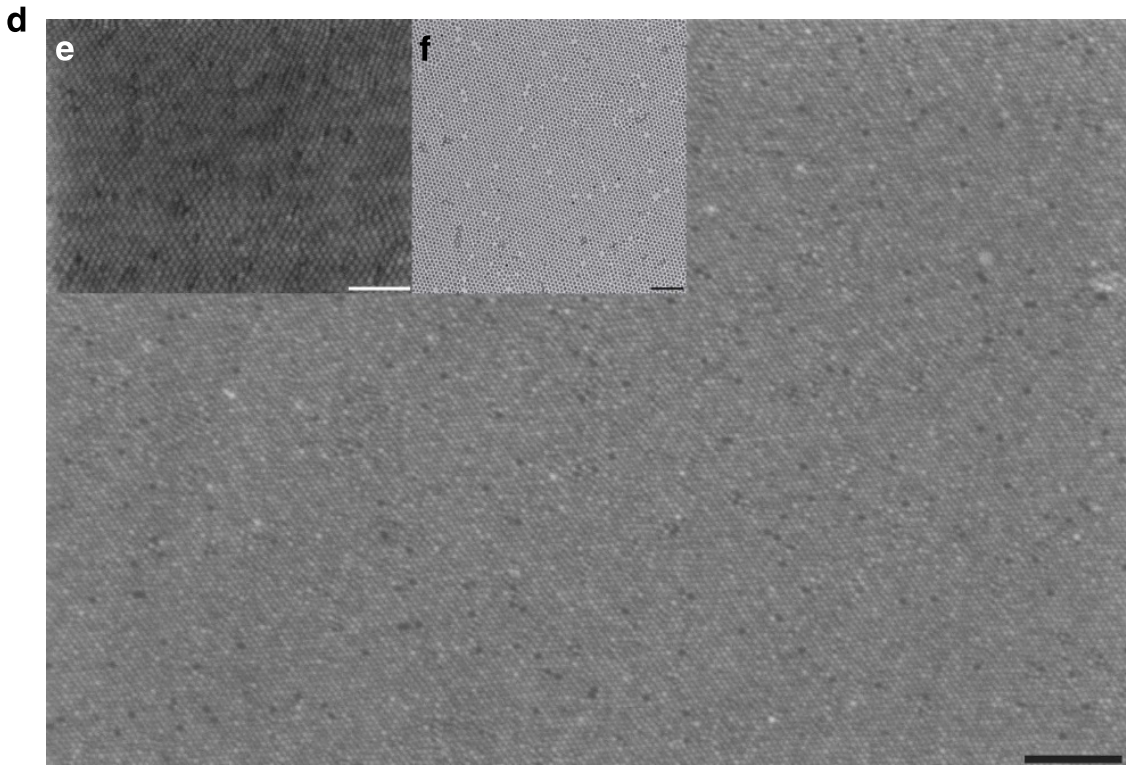

Figure 1 | Characterization and assembly of $\mathbf{A u}-\mathbf{C u}$ bimetallic nanoparticles. (a) TEM image of $\mathrm{AuCu}_{3}$ nanoparticles (scale bar, $100 \mathrm{~nm}$ ). Average size $11.20 \pm 1.65 \mathrm{~nm}$. (b) XRD patterns of Au-Cu bimetallic nanoparticles compared with diffraction patterns from the database (Au, JCPDS 03-065-2870; $\mathrm{Au}_{3} \mathrm{Cu}$, JCPDS 01-071-5023; $\mathrm{AuCu}$, JCPDS 00-025-1220; $\mathrm{AuCu}_{3}$, JCPDS 03-065-3249; Cu, JCPDS 00-004-0836). A small peak at 20 $37^{\circ}$ in the XRD pattern of $\mathrm{Cu}$ indicates the presence of a $\mathrm{Cu}_{2} \mathrm{O}$ shell. (c) Ultraviolet-visible spectra of $\mathrm{Au}$-Cu bimetallic nanoparticles. Dotted lines indicate the SPR peak of pure $\mathrm{Au}(\sim 523 \mathrm{~nm})$ and $\mathrm{Cu}(\sim 570 \mathrm{~nm})$ nanoparticles. (d) Scanning electron microscopy (SEM) image of a AuCu $\mathrm{u}_{3}$ nanoparticle monolayer transferred to a substrate using Langmuir-Schaefer technique (scale bar, $200 \mathrm{~nm}$ ). (e) Inset figure with a higher-magnification SEM image of a $\mathrm{Au}_{3} \mathrm{Cu}$ nanoparticle monolayer (scale bar, $100 \mathrm{~nm}$ ). (f) Inset figure with a TEM image of a Cu nanoparticle monolayer transferred to a TEM grid (scale bar, $100 \mathrm{~nm}$ ).

to the point where $\mathrm{Au}_{3} \mathrm{Cu}$ seems to exhibit the highest activity among the series. However, as the overall current density also includes the current from HER, it is difficult to determine which catalyst performs better for $\mathrm{CO}_{2}$ reduction just from this plot. Furthermore, as electrochemical $\mathrm{CO}_{2}$ reduction typically leads to a large number of chemical products, the overall current must be divided into individual products to get a quantitative understanding of the activity and selectivity as function of composition.

One way of doing this is to examine the Faradaic efficiencies (FE) for each product, which are shown in Fig. 2b-f. The results are interesting, as it is generally believed $\mathrm{Cu}$ is the only catalyst capable to produce a wide range of products ${ }^{10,14,18}$. Not only do the $\mathrm{Au}-\mathrm{Cu}$ bimetallic nanoparticles make products usually seen on $\mathrm{Cu}$, but the $\mathrm{FE}$ of these products shifts as the composition is changed (Supplementary Table 1). As the $\mathrm{Cu}$ content increases, the total number of products increases and the pure $\mathrm{Cu}$ nanoparticles exhibit the largest number in product type. Among the products that require more than two electron transfers, methane and ethylene are considered as major products that can be produced from $\mathrm{Cu}^{10,11}$. For methane and ethylene, the $\mathrm{FE}$ decreases substantially as more $\mathrm{Au}$ gets incorporated into the nanoparticle, eventually leading to a total loss of these products for nanoparticles with high concentrations of Au. Further, Fig. $2 \mathrm{~b}-\mathrm{f}$ reveals that the trends in FE for $\mathrm{CO}$ and $\mathrm{H}_{2}$ are opposite as the composition shifts. FE for CO increases with $\mathrm{Au}$ content, while $\mathrm{FE}$ for $\mathrm{H}_{2}$ decreases as the $\mathrm{Au}$ content 
a

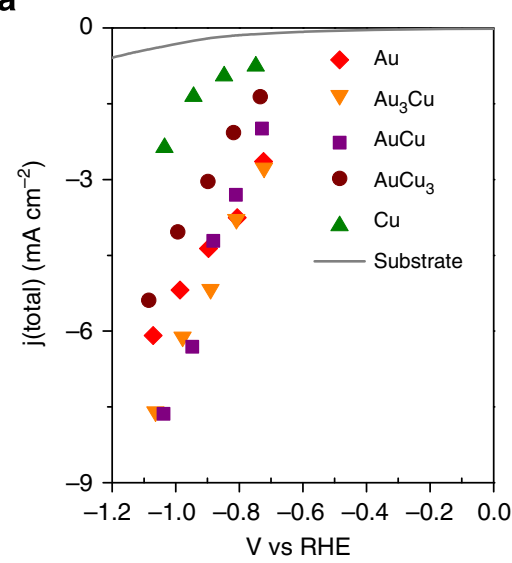

d

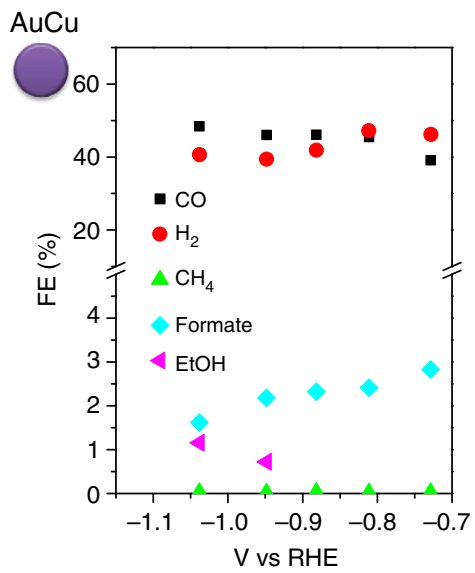

e b
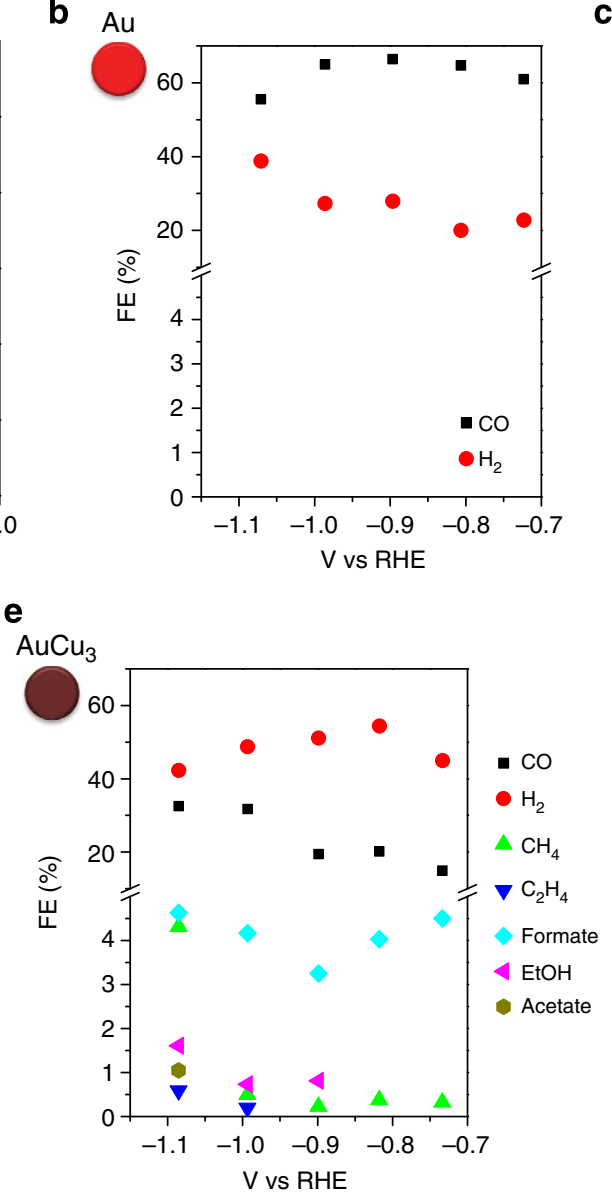

c $\mathrm{Au}_{3} \mathrm{Cu}$

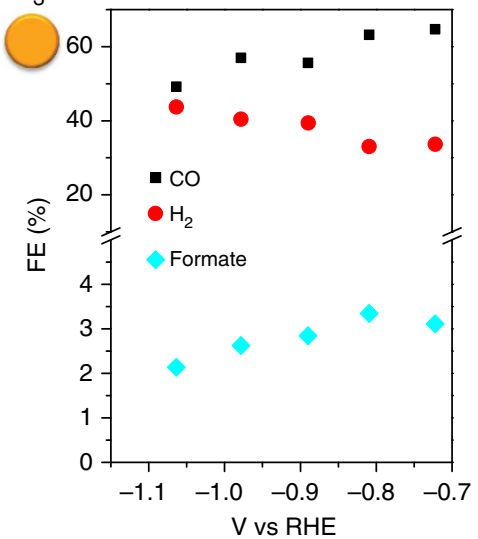

f

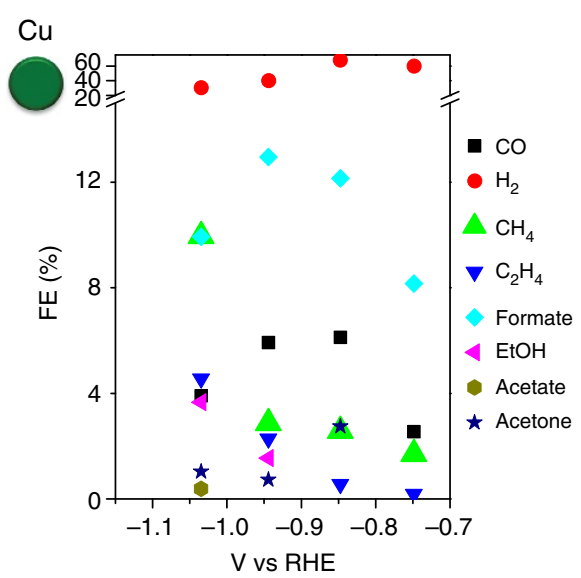

Figure 2 | Catalytic activities of Au-Cu bimetallic nanoparticles. (a) Total current density plot of Au-Cu bimetallic nanoparticles. Current density is from the geometric area of the electrodes. All measurements were under the same environment of $0.1 \mathrm{M} \mathrm{KHCO}_{3}\left(\mathrm{pH}^{6.8)}\right.$ at 1 atm $\mathrm{CO}_{2}$ and room temperature. The grey line indicates the activity of the bare substrate from linear sweep voltammetry $\left(50 \mathrm{mVs}^{-1}\right.$ ) stabilized after multiple cycles. For the nanoparticles, the current density is averaged for the first $5 \mathrm{~min}$ of each run to rule out any effects that mask their fundamental activity such as extensive bubble formation. On the plot is the average current density of multiple runs at each potential. See Supplementary Figs 4 and 5 . (b) FE for each product of $\mathrm{Au}$. (c) $\mathrm{Au}_{3} \mathrm{Cu}$. (d) $\mathrm{AuCu}$. (e) $\mathrm{AuCu}_{3}$. (f) $\mathrm{Cu}$. Other minor products were identified, such as methanol, acetaldehyde and glycoaldehyde with nanoparticles of higher Cu content, although not quantified. See Supplementary Table 1.

increases. For pure $\mathrm{Au}$ nanoparticles, the $\mathrm{FE}$ for $\mathrm{CO}$ is close to $\sim 65 \%$, which is consistent with other reports for $\mathrm{Au}$ nanoparticles of similar size ${ }^{23}$. In the case of formate, which is known as the largest molecular liquid product from $\mathrm{Cu}$, the trend seems to follow hydrocarbon species such as methane, although the decrease is not drastic.

Based on this analysis and comparison, the reactions that require a hydrogen atom binding to the carbon along the reaction pathway tend to have decreased in FE for their final products following the same trend for $\mathrm{H}_{2}$, while $\mathrm{FE}$ of $\mathrm{CO}$ shows the opposite trend where protonation happens at the hydroxyl end group of a carboxyl intermediate stabilized on the surface ${ }^{20-22}$. To protonate the carbon atom, a surface-stabilized proton has to be near the active site and this indicates that the product distribution in $\mathrm{CO}_{2}$ reduction might be related to the binding strength of hydrogen on the surface of a catalyst. In principle, we could expect that the binding strength of all the intermediates that occur along the reaction pathway would govern the activity/ selectivity, as it determines the interaction of the intermediates with the catalyst and lead into different reactions pathways and final chemical products. Therefore, at this point, it is reasonable to assume that by tuning the composition of $\mathrm{Au}-\mathrm{Cu}$ bimetallic nanoparticles, we are tuning the degree of stabilization of the intermediates on these nanoparticle surfaces, and consequently, different final chemical product profiles were observed.

Figure $3 \mathrm{a}$ compares the relative TOR for $\mathrm{CO}$ at $-0.73 \mathrm{~V}$ versus reversible hydrogen electrode (RHE) for these nanoparticles with different compositions (Supplementary Fig. 6). We found that the activity follows a volcano shape with a peak activity for $\mathrm{Au}_{3} \mathrm{Cu}\left(\mathrm{Au}_{3} \mathrm{Cu} \sim 93.1\right.$ times, $\mathrm{Au} \sim 83.7$ times and $\mathrm{AuCu} \sim 40.4$ times higher relative to $\mathrm{Cu}$ ). This trend can be understood by considering the elementary reaction steps from $\mathrm{CO}_{2}$ to $\mathrm{CO}^{22}$. In this reaction, $\mathrm{CO}_{2}$ is adsorbed onto the surface as $\mathrm{COOH}$ and further reduced to $\mathrm{CO}$. Therefore, the binding strength of $\mathrm{COOH}$ and $\mathrm{CO}$ essentially governs $\mathrm{CO}$ TOR. To enhance the $\mathrm{CO}$ production kinetics, a catalyst has to stabilize $\mathrm{COOH}$ more strongly relative to $\mathrm{CO}^{22}$, so that $\mathrm{CO}_{2}$ readily activates to $\mathrm{COOH}$ and desorbs as $\mathrm{CO}$. However, this is difficult to achieve with a monometallic catalyst because of the scaling relation, which shows that the binding strengths of different intermediates scale together ${ }^{21,39}$. Alloy catalysts, on the other hand, could potentially stabilize $\mathrm{COOH}$ relative to $\mathrm{CO}$ by forming an additional bond at the oxygen end with an oxophilic element (that is, $\mathrm{Cu}$ ) on the catalyst surface ${ }^{21,22}$. Based on this observation, the $\mathrm{CO}$ activity of $\mathrm{Au}-\mathrm{Cu}$ bimetallic nanoparticles can be explained in terms of (1) the electronic effect where the 


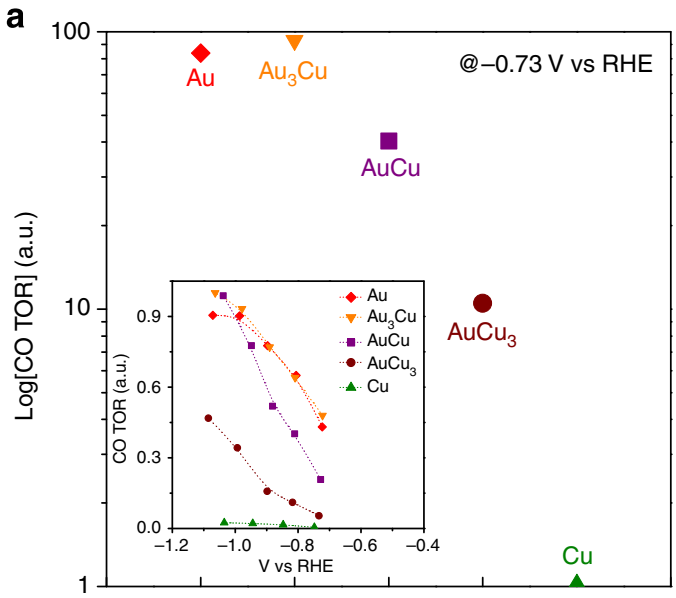

b

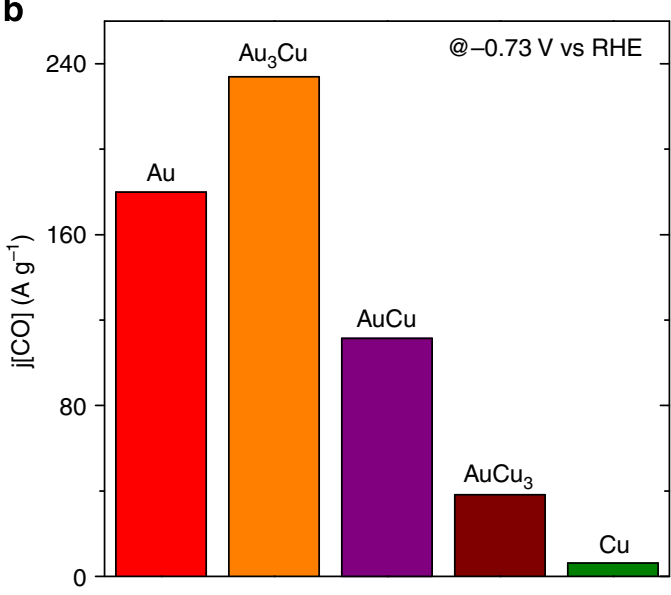

Figure 3 | Trends in TORs of Au-Cu bimetallic nanoparticles and their mass activity. (a) Relative TORs for carbon monoxide compared at $\sim-0.73 \mathrm{~V}$ vs RHE. TOR calculations are based on the partial current density and the TOR of $\mathrm{Cu}$ is set to one. Each data point is spaced equally apart on the $x$ axis and the TORs are plotted in log scale. Potential is chosen to minimize any mass transport effects. Inset shows relative CO TOR

(where all the data are normalized to the highest value) as a function of potential. See Supplementary Fig. 6 for other products. (b) CO mass activity of $\mathrm{Au}-\mathrm{Cu}$ bimetallic nanoparticles at $\sim-0.73 \mathrm{~V}$ vs RHE. Mass

activity is based on the overall mass of $\mathrm{Au}$ and $\mathrm{Cu}$. See Supplementary Fig. 10 and Supplementary Table 2.

binding of intermediates can be tuned using different surface composition and (2) the geometric effect that has to do with the local atomic arrangement at the active site, which allows the catalyst to deviate from the scaling relation.

The electronic effect on the binding strength of intermediates is due to the change in the electronic structure of a catalyst. For transition metals, the way their $d$-band interacts with the adsorbate determines the binding strength. The trend is that the more low lying (relative to the Fermi level) the $d$-band, the weaker the binding due to the occupancy of anti-bonding states ${ }^{39}$. Figure $4 \mathrm{a}$ is the surface valance band spectra of $\mathrm{Au}-\mathrm{Cu}$ bimetallic nanoparticles collected by high-resolution X-ray photoemission spectroscopy (XPS) on the nanoparticle monolayers. Using $\mathrm{Al} \mathrm{K \alpha}$ source, the binding energy was scanned from 0 to $20 \mathrm{eV}$ and each spectrum was collected over $\sim 1,000$ scans. The spectra reveal that the $d$-band and its centre of gravity gradually shift downwards from $\mathrm{Cu}$ to $\mathrm{Au}^{40}$. According to this trend, the binding strength for $\mathrm{COOH}$ and $\mathrm{CO}$, which is mainly from the bond between the active site and the carbon, should decrease as $\mathrm{Au}$ content increases. Then the binding strength to $\mathrm{Au}-\mathrm{Cu}$ bimetallic nanoparticles would lie in between $\mathrm{Au}$ and $\mathrm{Cu}$ following the scaling trend, which can also be estimated from the interpolation principle ${ }^{39}$. It is known that $\mathrm{Au}$ has the optimum binding strength for $\mathrm{COOH}$ and $\mathrm{CO}$ to reach peak activity among the transition metal catalysts for $\mathrm{CO}_{2}$ to $\mathrm{CO}$ conversion $^{22}$. Therefore, from the electronic effect, $\mathrm{Au}$ is expected to be at the peak of the volcano, while the activity scales down linearly to $\mathrm{Cu}$ as the composition shifts. However, we observe peak activity for $\mathrm{Au}_{3} \mathrm{Cu}$ and also activities higher for $\mathrm{AuCu}$ and $\mathrm{AuCu}_{3}$ than predicted from a trendline between $\mathrm{Au}$ and $\mathrm{Cu}$. In addition to the interesting trend in $\mathrm{CO}$ activity, the shift in selectivity and the presence of formate produced from $\mathrm{Au}_{3} \mathrm{Cu}$ but not pure $\mathrm{Au}$ needs to be understood from more than the electronic effect, considering the similar electronic structures of $\mathrm{Au}$ and $\mathrm{Au}_{3} \mathrm{Cu}$. These observations indicate that the activity is not solely determined from the electronic effect.

The geometric effect also plays an important role in determining catalytic activity, as it has to do with the atomic arrangement at the active site. The way the active site is configured can have a large effect on the binding strength of intermediates ${ }^{41}$. In the case of $\mathrm{Au}-\mathrm{Cu}$ bimetallic nanoparticles, further stabilization of $\mathrm{COOH}$ becomes possible by having a $\mathrm{Cu}$ atom adjacent to a $\mathrm{Au}-\mathrm{C}$ primary bond, where it can form a bond with the oxygen end of $\mathrm{COOH}$. As can be seen from highresolution TEM images and their fast fourier transform (Fig. $4 \mathrm{~b}$ and Supplementary Fig. 7), the nanoparticles have a uniform phase with $d$-spacings corresponding to their compositions and the lack of complete $\mathrm{Au} / \mathrm{Cu}$ atomic ordering, which is in agreement with other characterization methods discussed above. Further, the surface compositions of $\mathrm{Au}-\mathrm{Cu}$ bimetallic nanoparticles also follow the trend of their bulk compositions, evidenced from XPS spectra (Fig. 4c and Supplementary Fig. 8) at a grazing angle, which is highly surface sensitive. Thus, it is reasonable to assume that both elements are uniformly distributed throughout the particle according to their compositions and that these bimetallic nanoparticles are capable of providing active sites with further $\mathrm{COOH}$ stabilization. The electronic effect and geometric effect, operating synergistically here, lead to the observed volcano activity correlation with nanoparticle composition.

However, we did not observe a clear trend with the TOR for formate. Formate TOR was rather close in value among the different catalysts (Supplementary Fig. 6). This can also be understood in terms of the change in the binding energy of the intermediates. To produce formate, the active site should be capable of stabilizing both $\mathrm{COOH}$ and $\mathrm{H}$, so that there is a high probability of forming a bond between the carbon and the adsorbed proton. However, the relative free energy of adsorbed $\mathrm{CO}$ is lower than adsorbed $\mathrm{COOH}^{20-22}$. Therefore, $\mathrm{COOH}$ is more likely to be converted into $\mathrm{CO}$ rather than staying adsorbed as it is (Supplementary Fig. 9). As more Au gets incorporated into $\mathrm{Cu}$, the relative free energy difference between adsorbed $\mathrm{COOH}$ and $\mathrm{CO}$ narrows ${ }^{21}$. Further, alloy nanoparticles have the capability of further stabilizing $\mathrm{COOH}$ due to the geometric effect. Hence, there is higher probability for being adsorbed as $\mathrm{COOH}$. In contrast, the binding strength for $\mathrm{H}$ gets weaker as the $\mathrm{Au}$ content rises ${ }^{42}$. These two opposing effects lead to $\mathrm{HCOO}^{-}$ TOR being relatively unaffected by the compositional shift.

Products that require larger number of reaction steps, such as methane or ethylene, diminish significantly even with a slight shift in composition from pure $\mathrm{Cu}$. This might be due to the fact that these products require stabilization of both $\mathrm{CO}$ and $\mathrm{H}$. Adsorbed $\mathrm{CO}$ is protonated successively to evolve as hydrocarbon species $^{20}$. Cu seems to have the optimum binding strength for both of the adsorbed intermediates to facilitate the conversion. However, as the $\mathrm{Au}$ content increases, both intermediates 
a

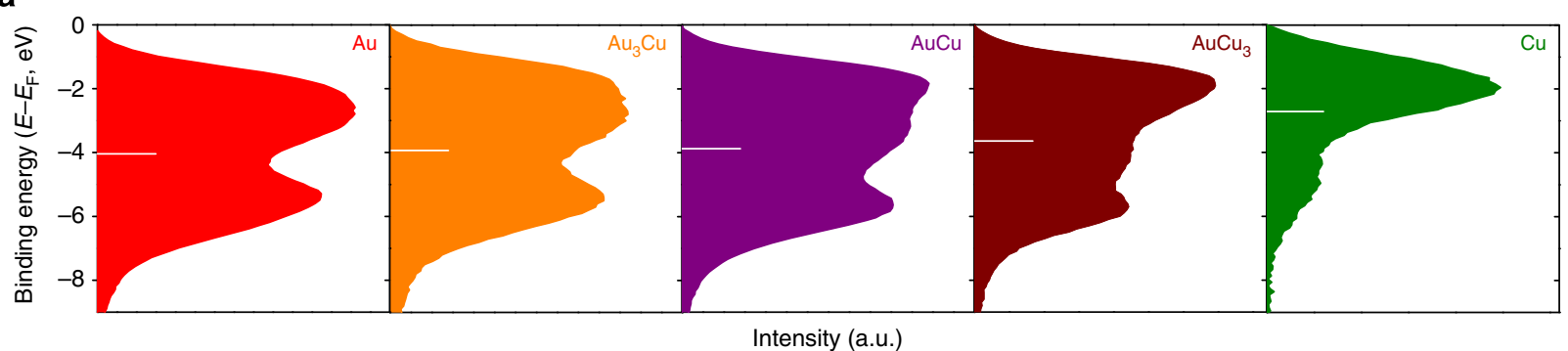

b

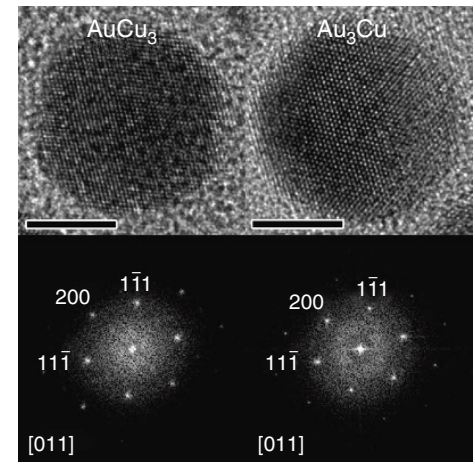

C

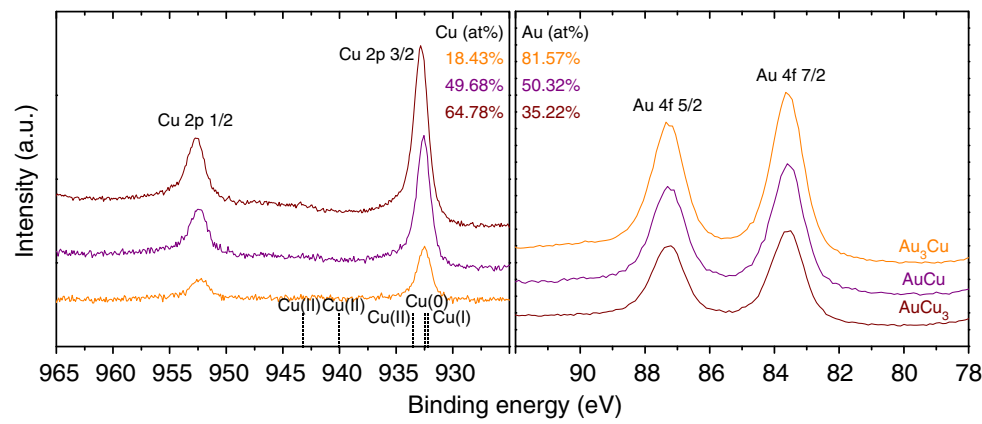

d

$\mathrm{Au}_{3} \mathrm{Cu}$

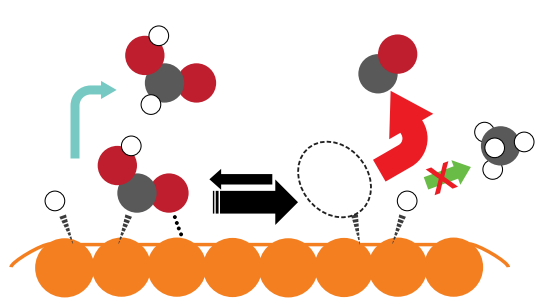

$\mathrm{AuCu}$

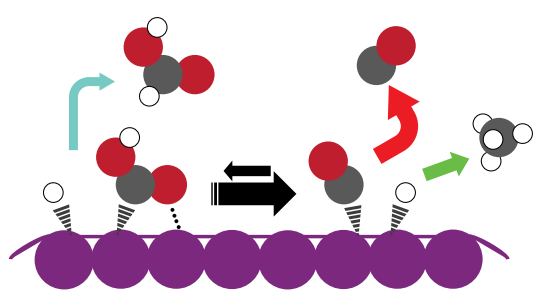

$\mathrm{AuCu}_{3}$

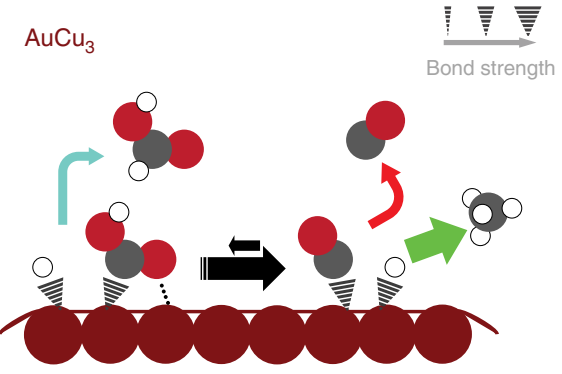

Figure 4 | Structural characterization of Au-Cu bimetallic nanoparticles. (a) Surface valence band photoemission spectra of Au-Cu bimetallic nanoparticles. All the spectra are background corrected. The white bar indicates its centre of gravity. For comparison, the upper limit of integration is fixed

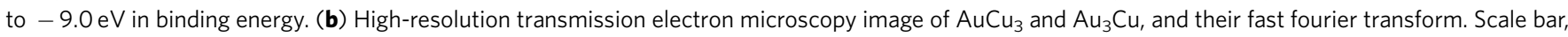
$5 \mathrm{~nm}$. (c) X-ray photoemission spectra at grazing angle $\left(85^{\circ}\right.$ ) on Au-Cu bimetallic nanoparticle monolayers. See Supplementary Fig. 8 for the survey spectra. (d) Schematic showing the proposed mechanism for $\mathrm{CO}_{2}$ reduction on the catalyst surface of Au-Cu bimetallic nanoparticles. Filled circles with grey is $\mathrm{C}$, red is $\mathrm{O}$ and white is $\mathrm{H}$. The relative intermediate binding strength is indicated by the stroke weight (on the top right corner). Additional binding between the $\mathrm{COOH}$ and the catalyst surface is presented as a dotted line. Arrows between the adsorbed $\mathrm{COOH}$ and adsorbed $\mathrm{CO}$ is to show the difference in probability of having $\mathrm{COOH}$ adsorbed on different types of surfaces. Coloured arrows indicate the pathway to each product: red for $\mathrm{CO}$, blue for formate and green for hydrocarbons. Larger arrows indicate higher turnover.

bind weaker, which reduces the TOR and leads to total loss of these products.

The use of our unique nanoparticle monolayer not only allows us to carry out the quantitative comparison of the $\mathrm{CO}_{2}$ reduction activity/selectivity as a function of composition, it also leads to high efficiencies by significantly enhancing mass activities (Supplementary Fig. 10 and Supplementary Table 2). $\mathrm{Au}_{3} \mathrm{Cu}$, which has the highest mass activity for $\mathrm{CO}$, outperforms conventional Au nanoparticle catalysts ${ }^{23}$ by more than an order of magnitude (Fig. 3b). There also have been efforts to reduce metal loading by using organometallic catalysts with large enhancements in mass activity ${ }^{19}$. The idea is to significantly reduce the metal loading by having a single metal atom coordinated to organic ligands that can perform the reduction of $\mathrm{CO}_{2}$. In the case of Ag, widely known as an efficient catalyst for $\mathrm{CO}$ production, this approach led to more than an order-ofmagnitude increase in mass activity compared with pure $\mathrm{Ag}$ nanoparticles. Our nanoparticle catalyst monolayers, characteristic of efficient loading, can operate at comparable activities to these organometallic catalysts for $\mathrm{CO}$ production (even considering the fact that $\mathrm{Au}$ is much heavier).

\section{Discussion}

The complexity of the reaction is clearly evidenced from the activity trends of $\mathrm{Au}-\mathrm{Cu}$ bimetallic nanoparticles. The TOR and the product distribution are governed by various intermediates that occur along the reaction pathway. However, we were able to show that this multi-parameter reaction could be described in terms of two effects (as shown in Fig. 4d), the electronic effect and the geometric effect. From these two factors, one can deduce how the intermediates will interact with the surface of a specific catalyst and hence tune its catalytic activity. To achieve high selectivity towards only $\mathrm{CO}_{2}$-reduced products, one should try to mitigate the proton-catalyst interaction (to suppress HER) and at the same time optimize the binding strength of the first few intermediates $(\mathrm{COOH}$ and $\mathrm{CO})$ in the pathway by using both effects. However, if the emphasis is on producing products with 
larger number of electron and proton transfers (that is, methane), the catalyst should be able to stabilize $\mathrm{CO}$ even further and allow coupling with the adsorbed proton or hydroxyl groups more efficiently. This might inevitably lead to higher production rates of $\mathrm{H}_{2}$, but if the atomic configuration on the active site prohibits proton-proton coupling, one might be able to achieve higher selectivity even for more complex products as well. In the design of a $\mathrm{CO}_{2}$ reduction catalyst, one should carefully balance how these two effects determine the interaction of intermediates with the catalyst so as to achieve better activity and selectivity.

We have used monodisperse $\mathrm{Au}-\mathrm{Cu}$ bimetallic nanoparticles in a unique platform to understand the trends of their fundamental activity for $\mathrm{CO}_{2}$ reduction. With its connection to the electronic structure and the local atomic environment, we could understand their catalytic activity systematically and have determined the factors that allow us to simplify the picture of the overall $\mathrm{CO}_{2}$ reduction. Further, our unique monolayer platform enabled us to measure mass activities significantly higher than catalysts structured by more conventional means. With the principles of catalyst design established, coupled with exceptional structuring of active sites, we believe unprecedented improvements in electrochemical $\mathrm{CO}_{2}$ reduction will be eventually fulfilled that will allow our goals of a sustainable energy society to finally become a reality.

\section{Methods}

Nanoparticle synthesis. Au-Cu bimetallic nanoparticles were synthesized via the co-reduction of metal precursors. For the $\mathrm{Au}-\mathrm{Cu}$ bimetallic nanoparticle (1:1 ratio), first, 1-octadecene (Sigma Aldrich) was heated to $130{ }^{\circ} \mathrm{C}$ for $30 \mathrm{~min}$ under nitrogen atmosphere. Next, $2 \mathrm{mmol}$ of oleic acid (Sigma Aldrich), $2 \mathrm{mmol}$ of oleylamine (Sigma Aldrich), $0.5 \mathrm{mmol}$ of gold acetate (Alfa Aesar), $0.5 \mathrm{mmol}$ of copper acetate (Sigma Aldrich) and $4 \mathrm{mmol}$ of 1,2-hexadecanediol (Sigma Aldrich) were added. Under the inert atmosphere, the mixture was heated to $200{ }^{\circ} \mathrm{C}$ and kept at that temperature for $2 \mathrm{~h}$ while stirring. Afterwards, it was further heated to $280^{\circ} \mathrm{C}$ for $1 \mathrm{~h}$. Then, the reaction was stopped by cooling it down to room temperature. Ethanol was added to the mixture to precipitate the synthesized nanoparticles and was washed several times with hexane and ethanol by centrifugation. For other compositions, the ratio of gold acetate to copper acetate was modified. The bimetallic nanoparticles showed significant stability against oxidation in ambient atmosphere and we kept the as-made nanoparticles in hexane. In the case of a pure $\mathrm{Cu}$ nanoparticle, synthetic procedures with tetradecylphosphonic acid (Sigma Aldrich) were followed instead, to inhibit its full conversion to $\mathrm{Cu}_{2} \mathrm{O}^{28}$. The nanoparticles were characterized by XRD (Bruker D8), TEM (Hitachi H-7650, JEOL 2100F), ultraviolet-visible spectroscopy (Vernier) and energy-dispersive $\mathrm{X}$-ray spectroscopy (EDAX).

Monolayer assembly. Nanoparticle assembly was conducted with methods modified from the previous report ${ }^{38}$. In the case of $\mathrm{AuCu}, 1.8 \mathrm{ml}$ of $\mathrm{AuCu}$ nanoparticle solution $\left(1 \mathrm{mg} \mathrm{ml}^{-1}\right.$ in hexane) was added to a solution mixture of $5 \mathrm{ml}$ of hexane and $3 \mathrm{ml}$ of toluene. Then, $600 \sim 700 \mu \mathrm{l}$ of the diluted nanoparticle solution was carefully spread on top of the water surface inside a custom-designed glass trough. The nanoparticle solution was left to evaporate through the opening at one end of the trough. After the solvent mixture dried, a large portion of the glass trough was covered with nanoparticle monolayer films. The monolayer films were transferred onto various substrates by the Langmuir-Schaefer method for further experiments. The transferred monolayers were imaged by TEM and scanning electron microscopy (JEOL JSM-6340F). XPS (PHI 5400) measurements were carried out on the monolayers to identify their electronic structure and surface composition. Using an $\mathrm{Al} \mathrm{K} \alpha$ source, with the pressure inside the chamber maintained below $\sim 4 \times 10^{-9}$ Torr, the spectra were collected at a pass energy of $17.9 \mathrm{eV}$. All the spectra collected were corrected using a Shirley background. Compositions were determined by considering the atomic sensitivity factors.

Centre of gravity calculation for the valence band spectra is conducted as $\frac{\int N(\varepsilon) \varepsilon d \varepsilon}{\int N(\varepsilon) d \varepsilon}$ in the range of $0 \sim-9.0 \mathrm{eV}$, where $N(\varepsilon)$ is the density of states.

Electrochemical measurement. All electrochemical measurements were carried out in our customized electrochemical setup. The cell has two compartments that are separated by an anion exchange membrane (Selemion AMV). Pt was used as a counter electrode and $\mathrm{Ag} / \mathrm{AgCl}(1 \mathrm{M} \mathrm{KCl})$ as a reference electrode. The nanoparticle monolayer on glassy carbon substrate was transferred inside the cell to test its $\mathrm{CO}_{2}$ reduction activity. Electrolyte $(33 \mathrm{ml}$ in the working compartment with gas headspace $\sim 7 \mathrm{ml}$ ) used was $0.1 \mathrm{M} \mathrm{KHCO}_{3}$ made from de-ionized water (Ricca
Chemical). Before every measurement, the working electrode compartment was purged with $\mathrm{CO}_{2}$ (Praxair, 5.0 Ultra high purity) for $30 \mathrm{~min}$ at a flow rate of $30 \mathrm{ml} \mathrm{min}^{-1}$. All the electrolysis was conducted at room temperature and $1 \mathrm{~atm}$ $\mathrm{CO}_{2}$ with $\mathrm{pH}$ of the electrolyte at 6.8. During chronoamperometry, effluent gas from the cell went through the sampling loop of a gas chromatograph (SRI) and was analysed in $20 \mathrm{~min}$ intervals to determine the concentration of gas products. The gas chromatograph was equipped with a molecular sieve $13 \mathrm{X}$ and hayesep D column with Ar (Praxair, 5.0 Ultra high purity) flowing as a carrier gas. The separated gas products were analysed by a thermal conductivity detector (for $\mathrm{H}_{2}$ ) and a flame ionization detector (for $\mathrm{CO}$ and hydrocarbons). Liquid products were analysed afterwards by quantitative NMR (Bruker AV-500) using dimethyl sulphoxide as an internal standard. Solvent presaturation technique was implemented to suppress the water peak. The concentration of liquid products was determined by the standard curves made from various known concentrations $(0.05$, $0.1,0.5$ and $1 \mathrm{mM}$ ) of chemicals purchased. FEs were calculated from the amount of charge passed to produce each product divided by the total charge passed at a specific time or during the overall run (for liquid products). Relative turnover was compared based on the partial current density for each product. Mass activities were calculated based on the overall mass of $\mathrm{Au}$ and $\mathrm{Cu}$ for each nanoparticle and the mass loading was determined assuming complete hexagonal packing on the substrate. Each measurement was conducted three times to check the consistency of our experiments. Electrochemical data presented here are the average values out of these multiple measurements.

\section{References}

1. Dresselhaus, M. S. \& Thomas, I. L. Alternative energy technologies. Nature 414, 332-337 (2001).

2. Gratzel, M. Photoelectrochemical cells. Nature 414, 338-344 (2001).

3. Lewis, N. S. \& Nocera, D. G. Powering the planet: Chemical challenges in solar energy utilization. Proc. Natl Acad. Sci. USA 103, 15729-15735 (2006).

4. Gasteiger, H. A. \& Marković, N. M. Just a dream-or future reality? Science 324, 48-49 (2009).

5. Yang, P. \& Tarascon, J.-M. Towards systems materials engineering. Nat. Mater 11, 560-563 (2012)

6. Faunce, T. A. et al. Energy and environment policy case for a global project on artificial photosynthesis. Energy Environ. Sci. 6, 695-698 (2013)

7. Liu, C., Dasgupta, N. P. \& Yang, P. Semiconductor nanowires for artificial photosynthesis. Chem. Mater. 26, 415-422 (2013).

8. Jhong, H.-R. M., Ma, S. \& Kenis, P. J. A. Electrochemical conversion of $\mathrm{CO}_{2}$ to useful chemicals: current status, remaining challenges, and future opportunities. Curr. Opin. Chem. Eng. 2, 191-199 (2013)

9. Hori, Y. in Modern Aspects of Electrochemistry Vol. 42, Ch. 3 (eds Vayenas, C. G., White, R. E. \& Gamboa-Aldeco, M. E.) 89-189 (Springer, New York, 2008).

10. Kuhl, K. P., Cave, E. R., Abram, D. N. \& Jaramillo, T. F. New insights into the electrochemical reduction of carbon dioxide on metallic copper surfaces. Energy Environ. Sci. 5, 7050-7059 (2012).

11. Gattrell, M., Gupta, N. \& Co, A. A review of the aqueous electrochemical reduction of $\mathrm{CO}_{2}$ to hydrocarbons at copper. J. Electroanal. Chem. 594, 1-19 (2006).

12. Rosen, B. A. et al. Ionic liquid-mediated selective conversion of $\mathrm{CO}_{2}$ to $\mathrm{CO}$ at low overpotentials. Science 334, 643-644 (2011).

13. Hori, Y. et al. "Deactivation of copper electrode" in electrochemical reduction of $\mathrm{CO}_{2}$. Electrochim. Acta 50, 5354-5369 (2005).

14. Hori, Y., Murata, A. \& Takahashi, R. Formation of hydrocarbons in the electrochemical reduction of carbon dioxide at a copper electrode in aqueous solution. J. Chem. Soc. Farad. Trans. 1 85, 2309-2326 (1989).

15. Li, C. W. \& Kanan, M. W. $\mathrm{CO}_{2}$ reduction at low overpotential on $\mathrm{Cu}$ electrodes resulting from the reduction of thick $\mathrm{Cu}_{2} \mathrm{O}$ films. J. Am. Chem. Soc. 134, 7231-7234 (2012).

16. Chen, Y., Li, C. W. \& Kanan, M. W. Aqueous $\mathrm{CO}_{2}$ reduction at very low overpotential on oxide-derived Au nanoparticles. J. Am. Chem. Soc. 134, 19969-19972 (2012).

17. Chen, Y. \& Kanan, M. W. Tin oxide dependence of the $\mathrm{CO}_{2}$ reduction efficiency on tin electrodes and enhanced activity for tin/tin oxide thin-film catalysts. J. Am. Chem. Soc. 134, 1986-1989 (2012).

18. Tang, W. et al. The importance of surface morphology in controlling the selectivity of polycrystalline copper for $\mathrm{CO}_{2}$ electroreduction. Phys. Chem. Chem. Phys. 14, 76-81 (2012).

19. Tornow, C. E., Thorson, M. R., Ma, S., Gewirth, A. A. \& Kenis, P. J. A Nitrogen-based catalysts for the electrochemical reduction of $\mathrm{CO}_{2}$ to CO. J. Am Chem. Soc. 134, 19520-19523 (2012).

20. Peterson, A. A., Abild-Pedersen, F., Studt, F., Rossmeisl, J. \& Norskov, J. K. How copper catalyzes the electroreduction of carbon dioxide into hydrocarbon fuels. Energy Environ. Sci. 3, 1311-1315 (2010).

21. Peterson, A. A. \& Nørskov, J. K. Activity descriptors for $\mathrm{CO}_{2}$ electroreduction to methane on transition-metal catalysts. J. Phys. Chem. Lett. 3, 251-258 (2012). 
22. Hansen, H. A., Varley, J. B., Peterson, A. A. \& Nørskov, J. K. Understanding trends in the electrocatalytic activity of metals and enzymes for $\mathrm{CO}_{2}$ reduction to CO. J. Phys. Chem. Lett. 4, 388-392 (2013).

23. Zhu, W. et al. Monodisperse Au nanoparticles for selective electrocatalytic reduction of $\mathrm{CO}_{2}$ to CO. J. Am. Chem. Soc. 135, 16833-16836 (2013).

24. Moshfegh, A. Z. Nanoparticle catalysts. J. Phys. D. Appl. Phys. 42, 233001 (2009).

25. Christophe, J., Doneux, T. \& Buess-Herman, C. Electroreduction of carbon dioxide on copper-based electrodes: activity of copper single crystals and copper-gold alloys. Electrocatalysis 3, 139-146 (2012).

26. Xu, Z., Lai, E., Shao-Horn, Y. \& Hamad-Schifferli, K. Compositional dependence of the stability of AuCu alloy nanoparticles. Chem. Commun. 48, 5626-5628 (2012).

27. Xie, J. et al. One-pot synthesis of monodisperse iron oxide nanoparticles for potential biomedical applications. Pure Appl. Chem. 78, 1003-1014 (2006).

28. Hung, L.-I., Tsung, C.-K., Huang, W. \& Yang, P. Room-temperature formation of hollow $\mathrm{Cu}_{2} \mathrm{O}$ nanoparticles. Adv. Mater. 22, 1910-1914 (2010).

29. Sra, A. K., Ewers, T. D. \& Schaak, R. E. Direct solution synthesis of intermetallic $\mathrm{AuCu}$ and $\mathrm{AuCu}_{3}$ nanocrystals and nanowire networks. Chem. Mater. 17, 758-766 (2005).

30. Motl, N. E., Ewusi-Annan, E., Sines, I. T., Jensen, L. \& Schaak, R. E. Au-Cu alloy nanoparticles with tunable compositions and plasmonic properties: experimental determination of composition and correlation with theory. J. Phys. Chem. C 114, 19263-19269 (2010).

31. Rice, K. P., Walker, E. J., Stoykovich, M. P. \& Saunders, A. E. Solventdependent surface plasmon response and oxidation of copper nanocrystals. J. Phys. Chem. C 115, 1793-1799 (2011).

32. Liu, S. \& Tang, Z. Nanoparticle assemblies for biological and chemical sensing. J. Mater. Chem. 20, 24-35 (2010).

33. Acharya, S., Hill, J. P. \& Ariga, K. Soft Langmuir-Blodgett technique for hard nanomaterials. Adv. Mater. 21, 2959-2981 (2009).

34. Mueggenburg, K. E., Lin, X.-M., Goldsmith, R. H. \& Jaeger, H. M. Elastic membranes of close-packed nanoparticle arrays. Nat. Mater. 6, 656-660 (2007).

35. Yamada, Y. et al. Nanocrystal bilayer for tandem catalysis. Nat. Chem. 3, 372-376 (2011).

36. Tao, A., Sinsermsuksakul, P. \& Yang, P. Tunable plasmonic lattices of silver nanocrystals. Nat. Nano 2, 435-440 (2007).

37. Wen, T., Booth, R. A. \& Majetich, S. A. Ten-nanometer dense hole arrays generated by nanoparticle lithography. Nano. Lett. 12, 5873-5878 (2012).
38. Wen, T. \& Majetich, S. A. Ultra-large-area self-assembled monolayers of nanoparticles. ACS Nano 5, 8868-8876 (2011).

39. Norskov, J. K., Bligaard, T., Rossmeisl, J. \& Christensen, C. H. Towards the computational design of solid catalysts. Nat. Chem. 1, 37-46 (2009).

40. Nemoshkalenko, V. V., Chuistov, K. V., Aleshin, V. G. \& Senkevich, A. I. Changes in energy structure of $\mathrm{Cu}_{3} \mathrm{Au}$ and $\mathrm{CuAu}_{3}$ alloys studied by the method of X-ray photoelectron spectroscopy. J. Electron Spectrosc. Relat. Phenom. 9, 169-173 (1976).

41. Siahrostami, S. et al. Enabling direct $\mathrm{H}_{2} \mathrm{O}_{2}$ production through rational electrocatalyst design. Nat. Mater. 12, 1137-1143 (2013).

42. Nørskov, J. K. et al. Trends in the exchange current for hydrogen evolution. J. Electrochem. Soc. 152, J23-J26 (2005).

\section{Acknowledgements}

This work was support by KAU (King Abdulaziz University) and made use of the imaging and nanofabrication facilities at the Molecular Foundry and the facilities at the NMR facility, College of Chemistry, University of California, Berkeley. D.K. acknowledges Samsung Scholarship for his funding. J.R. acknowledges the support from the National Science Foundation (NSF) under a graduate research fellowship (GRFP).

\section{Author contributions}

D.K. and P.Y. designed the experiments and wrote the paper. D.K. performed the experiments. J.R. and D.K. carried out the XPS analysis. Y.Y. and J.R. carried out the high-resolution TEM imaging. A.M.A and P.Y. guided the work. All authors discussed the results and commented on the manuscript.

\section{Additional information}

Supplementary Information accompanies this paper at http://www.nature.com/ naturecommunications

Competing financial interests: The authors declare no competing financial interests.

Reprints and permission information is available online at http://npg.nature.com/ reprintsandpermissions/

How to cite this article: Kim, D. et al. Synergistic geometric and electronic effects for electrochemical reduction of carbon dioxide using gold-copper bimetallic nanoparticles. Nat. Commun. 5:4948 doi: 10.1038/ncomms5948 (2014). 